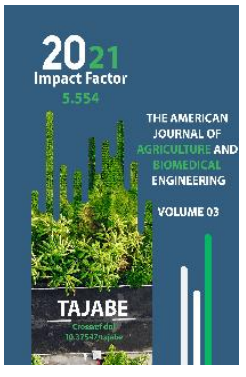

Journal Website: http://theamericanjour nals.com/index.php/taj abe

Copyright: Original content from this work may be used under the terms of the creative commons attributes 4.0 licence.

\section{Research On Cotton Fibre For The Production Of Quality Textile Products}

Muminov Najmiddin Shamsiddinovich

Doctor Of Technical Sciences, Head Of The Department Of Standardization And Certification Of Agricultural Products, Tashkent State Agrarian University, Tashkent, Uzbekistan

Alimova Zarina Muzaffarovna

Master Of ist Course Of The Department Of Standardization And Certification Of Agricultural Products Of The Tashkent State Agrarian University, Tashkent, Uzbekistan

Vasiev Xayrulla Ulugbekovich

Senior Teacher, Department Of “Metrology, Standardization And Product Management Systems", Andijan Machine-Building Institute, Andijan, Uzbekistan

\title{
ABSTRACT
}

The article presents the theoretical foundations of cotton and cotton fibre as the main strategic raw material for the production of quality textiles. It also highlights a brief history of the origin, properties, cultivation, collection and use of cotton. Information about the current state of the world market for the production and use of cotton. It will be argued that quality assurance is a complex problem that requires a lot of effort and responsibility on the part of all participants in the production of textile products. In addition, the methods and results of the study of quality indicators of cotton fibre - as the main raw material for textiles are presented.

\section{KEYWORDS}

Cotton, cotton fibre, history of cotton, fibre length, properties of cotton, cotton processing, world cotton market, quality indicators of cotton, textile industry, standardization, certification of cotton fibre.

\section{INTRODUCTION}

Cotton is a fibre of plant origin, which covers cotton seeds, the most important and cheapest of the common plant fibres [1]. Today cotton is the most important plant fibre used in the textile industry around the world (50-60\% of the total capacity).
Cotton fibres consist of $95 \%$ cellulose and 5\% fats and minerals. The world knows more than 50 varieties of cotton, but only 4 of them are grown and cultivated: 
- Gossypium hirsutum - annual herbaceous cotton, northernmost, gives short and coarse fibre;

- Gossypium arboreum - Indochinese treelike cotton, up to 4-6 m high;

- Gossypium barbadense - elite long fibre cotton from the islands, Barbados or Peruvian;

- Gossypium herbaceum - ordinary cotton, the most widespread.

Cotton is not picky but requires a long time of warm temperature without frost. That is why it is successfully grown in tropical and subtropical zones of the northern and southern hemispheres. The main suppliers of cotton for many years have been the United States, China, India, Pakistan, Brazil, although it is grown in 80 countries. Cotton is the most ancient spinning plant, the homeland of which is India, tropical regions of Asia, Africa and America. Cotton products were found in a Mexican cave near Tehuacan (early 6th millennium BC. Other sources attribute the domestication of cotton in ancient Mexico to 5-4 millennia BC.). Cotton was unknown to the Greeks and Arabs until the wars of Alexander the Great. During the Han Dynasty, the Chinese cultivated cotton in what is now Yunnan province. In Iran (Persia), the history of cotton goes back to the Achaemenid era (5th century BC). Cotton cultivation was widespread in Merv, Rey, and also in the Fars region. In Peru, the cultivation of a local cotton variety, Peruvian cotton (Gossypium barbadense), has become the basis for the development of coastal crops. The Spaniards, who arrived in Mexico and Peru in the early 16th century, found locals growing cotton and wearing clothes made from it. In Pakistan, cotton fabrics were found in Mohenjo-Daro, woven as far back as the third millennium BC. The abundance of natural dyes, the inhabitants of India, allowed them to dye fabrics in all colours of the rainbow.

The spread of cotton around the world was very slow. The Chinese were the first to know about cotton as early as 2.5 thousand years BC and used it as an ornamental plant.

\section{MATERIALS AND METHODS}

The first cotton mill was built at the end of the 18th century in Manchester (England). In the 15th century, thanks to trade relations with Bukhara and Samarkand, cotton became known in Russia, and in the 17th century, there was an unsuccessful attempt to grow cotton near Moscow. Ivan Tames was the first to produce cotton fabrics in Russia in the 172s. By the end of the 18th century, cotton production spread to the Tver, Ivanovo and Vladimir regions. The rival era of flax and cotton began, in which cotton fabrics took the leading position.

Cotton is a thermophilic tropical plant up to one and a half meters high. It tolerates drought well, but the soil must be moistened to obtain rich yields. For this, irrigation is required on cotton fields.

Cultivated cotton is a herbaceous plant with a height of $70 \mathrm{~cm}$ to $2 \mathrm{~m}$. There are many branches on its stem and therefore it looks like a bush. Cotton flowers are large, white, yellow or cream-coloured. The best, finelyfibred varieties have a reddish spot at the base of the petals. The fruit-boll is divided into 3-5 nests. Each nest contains 5 to 11 seeds. Each seed develops from 5 to 15 thousand fibres 3-5 $\mathrm{cm}$ long. It is for these fibres that cotton is grown. 
In Uzbekistan, mainly Mexican cotton is grown, which has a medium fibre length. The longer and finer the hairs, the higher the fibre grade. The best fibre is found in Uzbek and Egyptian cotton. The thinnest and longest fibre in Peruvian cotton. The varieties of finefibre flax are derived from it. This type of cotton is especially prized. 16 thousand meters of fabric are obtained from one ton of finestaple cotton, and only 8.5 thousand meters from 1 ton of medium-staple cotton. Cotton fibre is used to make fabrics, knitwear, drive belts, ropes, car tires, fishing nets, you can't list everything.

Cotton seeds also do not disappear. Cottonseed oil is squeezed out of them. And pomace flour helps to harvest a new cotton crop: it is an excellent fertilizer. Cleaned cotton is generally classified according to fibre length, stretch and degree of soiling. According to the degree of stretching and pollution, cotton fibres are divided into 7 groups, where 0 is selected cotton.

Cotton fibre is a single plant cell that develops from the skin of a seed. The thickness of one fibre is 15-25 microns; depending on the length of the fibre (from 5 to $60 \mathrm{~mm}$ ), the yarn made from it is classified as:

- $\quad$ Short-fibre (up to $27 \mathrm{~mm}$ );

- Medium-fibre (30-35 mm);

- Long-fibre (35-50 mm) and are subjected to various treatments.

The fibre is a hollow tube (which explains the poor thermal conductivity), twisted around its axis (7-10 times per $1 \mathrm{~mm}$ ). As the fibre matures, cellulose deposits build-up, resulting in increased fibre strength. In terms of chemical composition, 95\% consists of cellulose, the remaining $5 \%$ are fatty and mineral impurities [2].

Consideration of the main properties of cotton:

- Possesses high hygroscopicity (ability to absorb moisture). When swelling, the fibre increases by about $40 \%$ in volume. Unlike other fabrics, cotton does not decrease its strength when wet, but increases (by about $15 \%)$.

- In terms of strength, it is comparable to silk (if we compare the breaking load of natural fibres); inferior in strength to flax and superior to wool.

- Like all natural fabrics, it is sensitive to light - after 940 hours of exposure to sunlight, the strength is halved.

- More than silk, it is sensitive to prolonged exposure to high temperatures - after three days of heating to $150{ }^{\circ} \mathrm{C}$, the strength is halved.

- Thermoplastic - able to "remember" the shape after heating (in other words, it can be ironed), which allows you to add cotton to suit fabrics made of synthetic fibres to improve properties.

- Possesses good heat-shielding characteristics due to the complete structure of the fibre.

- Untreated fabrics are easily wrinkled and abraded; abrasion resistance is solved by adding synthetic fabrics (nylon); increased creasing is eliminated after the so-called wrinkle-free finishing with ureaformaldehyde or melamine-formaldehyde resin.

- Like other natural fibres, it does not dissolve in organic solvents (for example, 
formic acid, vinegar, alcohol), which makes it possible to use these readily available reagents for cleaning difficult stains on cotton fabrics at home. However, it is sensitive to the action of inorganic acids and alkalis;

- Sensitive to the activity of microorganisms (in other words - rots).

- When burning, cotton gives off a burnt paper smell ${ }^{[4]}$. The recommended temperature for wet heat treatment is 130 ${ }^{\circ} \mathrm{C}$.

Advantages of cotton fibre fabrics: low cost of production, good hygienic properties (in terms of the combination of hygroscopicity and air permeability), the ability to shrink.

Disadvantages: susceptibility to pilling, abrasion, creasing (without special treatment), sensitivity to light (like most natural fabrics), a large number of irreversible deformations (stretching of the product) due to a small amount of elastic deformation.

In the middle of the 2oth century, the republics of Central Asia, and primarily Uzbekistan, were turned into a "cotton granary" of the Soviet Union, providing raw materials for light industry enterprises.

By the early 1970s. All land suitable for cultivation in Uzbekistan was given for cotton growing. The unprecedented withdrawal of water for irrigation led to the disappearance of the Aral Sea, and the use of toxic fertilizers and pesticides in monoculture conditions and the rejection of crop rotation turned into environmental disasters [3].

Before the plant produces soft fibre, it goes through several stages:
1. Formation of a bud from which a flower will grow over time.

2. Flower and its pollination.

3. Growth of the seedbox and the formation of cotton fibres from it. The fibres begin to grow only after pollination. The capsule expands, bursts, releasing cotton fibres.

III-considered cultivation and irrigation have led to the desertification of large areas in Uzbekistan, for which cotton is the main export commodity. Water withdrawal for irrigation, including cotton fields, led to the tragedy of the Aral Sea.

Nowadays, cotton can be grown in such a way as to have not only the usual yellowish-white colour but also red, green and brown (naturally dyed cotton).

It is estimated that $300-500$ thousand people are poisoned by pesticides on cotton plantations in the world every year, 20 thousand of them die. Due to the widespread use of toxic defoliants in cotton-growing areas, infant mortality is extremely high and the number of newborns with defects is high.

Cotton picking begins when the box bursts and white, fluffy fibre appears from it. Collect the fibre with seeds and fluff. All this mass is called raw cotton. Picking cotton under the scorching sun is very difficult. The work of the pickers was made easier by the cotton pickers. Cotton ginners clean cotton from bolls, branches, leaves and other litter. After opening the bolls by $80 \%$, the cotton is processed to accelerate ripening; cottonpicking begins after opening the bolls by $95 \%$. Hand-picking cotton (India, 2005); Unloading Freshly Harvested Cotton (Texas) Then the 
cotton fibre is separated from the seeds, from which the oil is squeezed out. It is used for food, industrial oils, soap, candles, and other products are made from it. When ripe, the cotton boll opens. The fibre together with unseparated seeds - raw cotton - is collected at the cotton collection points. In developing countries, cotton is traditionally harvested by hand. The average cotton yield is $30 \mathrm{c} / \mathrm{ha}(3 \mathrm{t} /$ ha). Maximum - $50 \mathrm{c} / \mathrm{ha}$ ( $5 \mathrm{t} / \mathrm{ha}$ ).

This is followed by the separation of fibres along the length: cotton fibre - fibres longer than $20 \mathrm{~mm}$, fluff (lint) - less than $20 \mathrm{~mm}$, and underfills (delint) - less than $5 \mathrm{~mm}$.

Cotton is used for textile processing to produce cotton yarn. Cotton is used to produce fabrics, knitwear, threads, cotton wool and more. Down and down cotton is used in the chemical industry as a raw material for the manufacture of artificial fibres and threads, films, varnishes, etc.

In the first half of the 19th century, cotton paper (i.e. cotton wool) was inserted into the ears for the prevention and treatment of colds [4].

Everyone knows that textiles made from 100\% cotton (for example, cotton towels, bed linen, bathrobes) create special comfort.

\section{Cotton fibres are used for the production of:}

- Elite, thin fabrics - only long-staple cotton is used for them;

- Cheaper fabrics, such as calico, chintz, etc. - use medium staple cotton;

- Knitwear - short-fibre cotton can also be used in the manufacture (this sometimes explains its lower durability), for the strength they add synthetic components;

- Medical cotton wool;

- Batting;

- Cotton filler for pillows, blankets and mattresses - modern methods of careful processing of cotton fibre allow to obtain a material that perfectly holds its shape, does not cake and is environmentally friendly.

Table 1. List of countries producing cotton in the world

\begin{tabular}{ccc}
\hline Country & Production (Tons) & Production per person (kg) \\
\hline India & 6188000 & 4,63 \\
PRC & 6178318 & 4,433 \\
USA & 3593000 & 10,962 \\
Pakistan & 2374481 & 11,762 \\
Brazil & 1412227 & 6,74 \\
\hline Uzbekistan & 1106700 & 33,892 \\
\hline
\end{tabular}




\begin{tabular}{ccc}
\hline Australia & 885100 & 35,334 \\
\hline Turkey & 846000 & 10,469 \\
\hline Argentina & 327000 & 7,349 \\
\hline
\end{tabular}

The main consumer of cotton in the textile industry. China accounts for about 35\% of global cotton consumption. The demand for cotton is not compensated by China's resources, forcing it to import raw materials.

The largest exporter of cotton in the period 2001-2005 is the United States (slightly less than $40 \%$ of all exports), followed by the African countries of the "zone of the franc" (9$13 \%)$.

In 2017, the global raw cotton market was estimated at $\$ 13.2$ billion. The main exporter in the United States, accounting for almost $45 \%$ of all cotton exported in 2017 , followed by India 13\%, Australia 11\%, Brazil 10\% and Greece 3\%; Uzbekistan, Burkina Faso, Cameroon, Benin and Turkmenistan round out the top ten with $1 \%-1.5 \%$.

Major importers: China 16\%, Vietnam 15\%, Turkey 12\%, Bangladesh $12 \%$ and Indonesia 9.5\%, India 6.9\%, Pakistan 6.2\%, Mexico 3.1\%, Thailand $2.9 \%$, South Korea $2.8 \%$.

The qualitative and quantitative indicators of the produced cotton fibre and other byproducts largely depend on the level of development of technology and technology for the primary processing of raw cotton, including the processes of material preparation (drying and cleaning) and the final operation (ginning and packaging). The quality of raw cotton during transportation and storage deteriorates due to the non-use of available funds and untimely implementation of preventive measures [5]. In the cotton trade, the first and most important factor is the quality of the fibre from the bale. The quality of the yarn is extremely important to the spinner as it will determine the cost of processing the fibre into yarn. This is why spinners need accurate fibre quality data. It is a business in which a single mistake in cotton classification can cost both buyer and seller millions of dollars. This is how a reputation can be destroyed in a matter of minutes.

$\mathrm{HVI}$ has an unrivalled track record of producing accurate, reliable test results in cotton grading. Getting the right quality score is like building and strengthening your reputation.

A significant contribution to improving the quality of fibre was brought about by the improvement of the system of classification of raw cotton and finished cotton products, carried out jointly by «Uzpakhtasanoat» JSC and Uzbek centre "Sifat». An important step towards increasing the level of production and product quality was the introduction of the international quality management system in accordance with ISO 9001 in all territorial associations of «Pakhtasanoat» and at 34 cotton factories in the industry. 
With the introduction of the state standard O'z DSt 604 in the 1994 season, the share of grade I cotton fibre increased significantly. If before 1994 the share of the first grade accounted for no more than $30-40 \%$ of the fibre volume, then after the introduction of the standard, the share of grade I fibre increased to $65-75 \%$.

An independent assessment of the quality of cotton fibre produced in the country is carried out by the Center for Certification and Quality Control of Cotton Fibre "Sifat". Since 2001, the centre has been conducting 100\% purchased tests in laboratories equipped with HVI systems, and today it controls and certifies the quality and weight of each bale of fibre. Over the years, Sifat has become a member of the leading European cotton associations, an authoritative partner of foreign cotton companies and firms.

Measures to improve breeding work, zoning of cotton varieties that are exclusively in demand on the world market, together with the improvement of the technology for the preparation of sowing seeds and primary processing of cotton, contributed to the improvement of quality indicators and the range of cotton fibre.

Improving the assortment of produced fibre, the main share of which falls on the ranges of capes to the price, made it possible to significantly increase foreign exchange earnings from the sale of cotton fibre.

The analysis shows that the consumer properties of cotton fibre in terms of grade, class, length, micro neuro, strength and colour generally correspond to the requirements of the world market. In total, the Republic receives tens of millions of dollars annually by improving its quality.

\section{CONCLUSIONS AND RECOMMENDATIONS}

To produce high-quality products and ensure their competitiveness in the world market, it is necessary to equip industrial enterprises with modern foreign equipment to replace old equipment, comply with the requirements for production, packaging, storage and transportation, as well as ensure the stability of product quality. These requirements are formalized by national and international regulatory documents of different levels.

The modern theory of quality management is that quality management activities cannot be effective after the production of a product, this activity must be carried out in the production process.

This means that the quality of the product must be strictly maintained at all stages of technological processes in enterprises for receiving, cleaning and processing cotton, as well as in the textile industry. Only then will we be able to produce quality products that meet international standards.

To regularly maintain the quality indicators of cotton fibre in the world market at the level of world standards, it is important to organize breeding work, the use of high technologies and agricultural technologies associated with a timely increase in cotton yields, ensuring the quality of finished products at cotton-picking stations, cotton ginning and processing enterprises, in the field of textiles and light industry, analyze the activities of the testing 
laboratory for their comprehensive assessment.

It is known that the quality of cotton products depends to a large extent on the activities of cotton-receiving units, ginning and processing enterprises.

The organization and conduct of work based on modern requirements for laboratories for monitoring and assessing the quality of cotton in the activities of cotton receiving points, cotton ginning and processing enterprises is an urgent problem today.

Therefore, it is important to study and assess the level of influence of preparation, storage and primary processing of raw cotton on the quality of the final product and the introduction of rational technology to eliminate the existing shortcomings.

\section{REFERENCES}

1. Prokhorov, A. M. (1970). Great Soviet Encyclopedia.

2. Gordon, S., \& Hsieh, Y. L. (Eds.). (2006). Cotton: Science and technology. Woodhead Publishing.

3. Wang, H., Siddiqui, M. Q., \& Memon, H. (2020). Physical Structure, Properties and Quality of Cotton. In Cotton Science and Processing Technology (pp. 79-97). Springer, Singapore.

4. Holliev, E. (2011). Drought and Cotton Varieties in Zaravshan Valley of Uzbekistan. International Journal of Applied, 6(3), 217-221.

5. International ISO standards for cotton and cotton fibre, according to the methods of research, their quality. 